\title{
ANTIOBESITY EFFECTS OF HUMAN SOLUBLE LEPTIN IN MICE NOURISHED WITH A HIGH-FAT/HIGH FRUCTOSE DIET
}

\author{
${ }^{1}$ Chimal-Vega, B., ${ }^{2}$ N. Paniagua-Castro, ${ }^{2}$ J.C. Perez-Rebollar, \\ ${ }^{1}$ J.P. Carrillo-Vazquez, ${ }^{1}$ A. Zamorano-Carrillo and ${ }^{1}$ C.G. Benitez-Cardoza \\ ${ }^{1}$ Laboratory of Investigation Biochemistry and Computational Biophysics, \\ Department of Molecular Biomedicine and Doctoral Program of Biotechnology, \\ ENMH-IPN, Mexico City, Mexico \\ ${ }^{2}$ Department of Physiology ENCB-IPN, Mexico City, Mexico
}

Received 2014-05-12; Revised 2014-06-24; Accepted 2014-07-08

\begin{abstract}
Leptin is a hormone that regulates energy balance. Since its discovery two decades ago, several efforts have been made to fully understand its role in metabolic regulation of feeding behavior, reproduction, glucose homeostasis, immune function, bone formation, lipid metabolism, among others. Its use as a therapeutic option in obese patients is still limited due to the syndrome known as Leptin resistance. In this study, we determined that the treatment of a soluble form of human Leptin (W100E) reduced food intake, body weight and triglycerides levels, but increased HDL-cholesterol levels on obese mice subjected to high-fat/high-fructose diet. In contrast, treatment with soluble human Leptin increased food intake but did not increase body weight and total-cholesterol in mice with normal diet. When stopping the treatment with human W100ELeptin, it was detected a significant increase in body weight in all groups of mice apart from the control, indicating a rebound effect. The results contribute to the understanding of how to increase Leptin sensitivity and in consequence to overcome Leptin resistance syndrome. This might be relevant in offering more evidence of the potential use of the Leptin in the treatment against obesity and overweight conditions.
\end{abstract}

Keywords: Leptin, W100E, Triglycerides Levels, HDL-Cholesterol High-Fat/High-Fructose Diet

\section{INTRODUCTION}

Overweight and obesity are major health problems spread worldwide. It is estimated that in some countries the prevalence of obesity is higher than $30 \%$ of their populations, some examples are Mexico (32.8\%), USA $(31.8 \%)$, Siria $(31.6 \%)$, Venezuela and Libia (30.8\%), (http://www.who.int/topics/obesity/en/;

httRp://www.fao.org/publications ISSN 0081-4539; Barrera-Cruz et al., 2013). In addition, overweight accounts for similar percentages in these countries (http://www.who.int/topics/obesity/en/). Both conditions are associated to the development of chronic diseases such as hyperlipidemias, type II diabetes and cardiovascular complications (Sowers, 2003; Sánchez, 2005; Carrillo-Vazquez et al., 2013) implying high economic costs to health systems of mentioned nations. It is well recognized that obesity and overweight are complex health problems than a mere balance between food intake and energy expenditure (Shapiro et al., 2008; Ahima and Flier, 2000) and that they cannot be solved by solely trusting in the willpower of individuals.

Corresponding Author: C.G. Benitez-Cardoza, Laboratory of Investigation Biochemistry and Computational Biophysics,

Department of Molecular Biomedicine and Doctoral Program of Biotechnology,

ENMH-IPN, Mexico City, Mexico 
Several hormones have been described to regulate appetite and metabolism involving Leptin, ghrelin, insulin, Peptide YY3-36 (PYY3-36), Chole Cysto Kinin (CCK) among others (Bell et al., 2005). Leptin is one of the most influential adipose derived hormones that participate in energy balance (Houseknecht et al., 1998). The Leptin gene encodes for a 167 amino acid protein with 21 amino acid signal sequence (Varnerin et al., 1998). Leptin is mainly produced in white adipose tissue, followed by brown adipose tissue, placenta, ovaries, skeletal muscle, stomach, mammary epithelial cells, bone marrow, pituitary and liver (Prins, 2002; Masuzaki et al., 1997; Paz-Filho et al., 2010). The effect of Leptin in energy balance is evidenced by the extreme obese phenotype caused by Leptin scarcity and by the dramatic decrease in food intake and body weight that occurs upon treatment of this condition with Leptin administration (Morrison, 2008). Even though, obese individuals usually show increased levels of Leptin in serum and respond unsuccessfully to Leptin treatment (Bence et al., 2006). In addition, some studies have shown that exogenous Leptin administration instead of providing a cure, it might contribute to obesity (Aijälä et al., 2013). It has been observed that Leptin worsens obesity of high-fat diet-induced animals, whereas rats on a lowfat diet exhibited the expected Leptin-induced reduction in body weight (Flores et al., 2006). Also, it seems that increasing energy expenditure by exercise might have a synergetic effect to improve the response to exogenous Leptin administration (Lo et al., 2005). Some authors have proposed that the reduced clinical efficacy of Leptin results from its short circulating half-life, low potency and poor solubility (Lo et al., 2005). Also, poor solubility hindered to readily crystallize wild type human Leptin. However, this hormone could be structurally described by substituting Trp for Glu at position 100 (Zhang et al., 1997). Leptin W100E is the first soluble Leptin described and it has been mentioned as a hormone with similar biological activity but higher propensity to crystallize (Zhang et al., 1997; Haglund et al., 2012). Nevertheless, to our knowledge, the effect of W100E Leptin treatment (sequence shown in Fig. 1), on the food intake, body weight and lipid profile on mice with normal and hypercaloric diets has not been explicitly presented. Indeed, most reports showing the use of Leptin treatment against obesity utilize recombinant methionyl human Leptin depicted as metre Leptin (Vatier et al., 2012; Seuk Moon et al., 2011; US 2013/0203661 A1). As one single amino acid mutation can alter physicochemical properties, conformation, as well as biological activity, we were interested in to describe in a comprehensible manner the antiobesity effects of the construct W100E Leptin on mice feed with normal or high fat/high fructose diets. These results are helpful to better understand how to overcome short circulating halflife, low potency and poor solubility of human Leptin. In consequence, they bring us closer to spreading the use of this hormone as a therapeutic option against obesity and overweight.

\section{MATERIALS AND METHODS}

\subsection{Human W100E-Leptin}

The gene encoding for human Leptin was cloned in a modified version of $\mathrm{pET} 19 \mathrm{~b}$ vector (Novagen). This vector encodes for a 10-His-tag protein and a PreScission Protease (GE Health Care Life Sciences) cleavage site. The W100E mutant construct was obtained by Quik Change (Stratagene) site-directed mutagenesis kit using the oligonucleotides Fw 5' AGC TGC CAC TTG CCG GAG GCC TCT GGC CTG GAG 3' and Rv 5' CTC CAG GCC AGA GGC CTC CGG CAA GTG GCA GCT 3' and following the manufacturer's protocol. E. coli cells strain BL21 (DE3) pLysS (Novagen) harboring the pET19b-human-W100E-Leptin- plasmid were grown at $37^{\circ} \mathrm{C}$ in $2 \mathrm{X}$ YT medium complemented with ampicillin $\left(100 \mu \mathrm{g} \mathrm{mL}^{-1}\right)$ to an OD600 of 0.6 followed by induction with $1 \mathrm{mM}$ IPTG and further incubation for $16 \mathrm{~h}$ at $37^{\circ} \mathrm{C}$. After harvesting by centrifugation, the cells were disrupted by sonication. Crude inclusion body pellets were obtained and washed twice with $50 \mathrm{mM}$ Tris-HCl $100 \mathrm{mM} \mathrm{NaCl}, 1 \mathrm{mM}$ EDTA pH 8.0, $1 \%$ Triton $\mathrm{X}-100$ at $4{ }^{\circ} \mathrm{C}$. The remaining insoluble inclusion body pellet was dissolved in $50 \mathrm{mM}$ Tris-HCl, pH 8.0, complemented with $8 \mathrm{M}$ urea and centrifuged to clarify. Afterwards, the sample was extensively dialyzed against a solution with composition $4.3 \mathrm{mM} \mathrm{Na} 2 \mathrm{HPO} 4,1.4 \mathrm{mM}$ $\mathrm{KH} 2 \mathrm{PO} 4,137 \mathrm{mM} \mathrm{NaCl}$ and $2.7 \mathrm{mM} \mathrm{KCl}$ (solution A) mixture of oxidized $(0.2 \mathrm{mM})$ and reduced $(2 \mathrm{mM})$ glutathione was added to the protein preparation. Leptin protein was purified by nickel-affinity chromatography (Ni-NTA Agarose QIAGEN). After extensively washing with $50 \mathrm{mM}$ imidazole, bound protein was eluted with a solution A complemented with $250 \mathrm{mM}$ imidazole and 2 $\mathrm{M} \mathrm{NaCl}$. For the removal of the 10-His tag, the purified proteins were dialyzed against buffer solution containing $10 \mathrm{mM}$ KH2PO4, $10 \mathrm{mM}$ K2HPO4 pH 8.0 (solution B) and treated with Pre Scission Protease (GE Healthcare Life Science), following the manufacturer's protocol. His tags and non-cleaved Leptin were eliminated by high resolution ion exchange chromatography (Mono Q 5/50 GL, GE Healthcare Life 
Science) eluting with solution B complemented with $2 \mathrm{M}$ $\mathrm{NaCl}$ to form a saline gradient. After cleavage, the resulting sequence contains a Gly and a Pro at the $\mathrm{N}$ terminus as describing in Fig. 1.

Homogeneity of Leptin-W100E was confirmed by SDS-PAGE. The purified protein was extensively dialyzed against with solution B. All reactants were molecular biology grade and the water used was distilled and deionized.

\subsection{High-Fat/High Fructose Diet}

The high-fat food was made by supplementing 35\% lard to a ground standard diet. Fructose (Cedrosa SA Mexico) solution (60\%) was given daily by gavage. Food consumption was measured every day and body weight was measured once each two days. The composition of the diets is presented in Table 1.

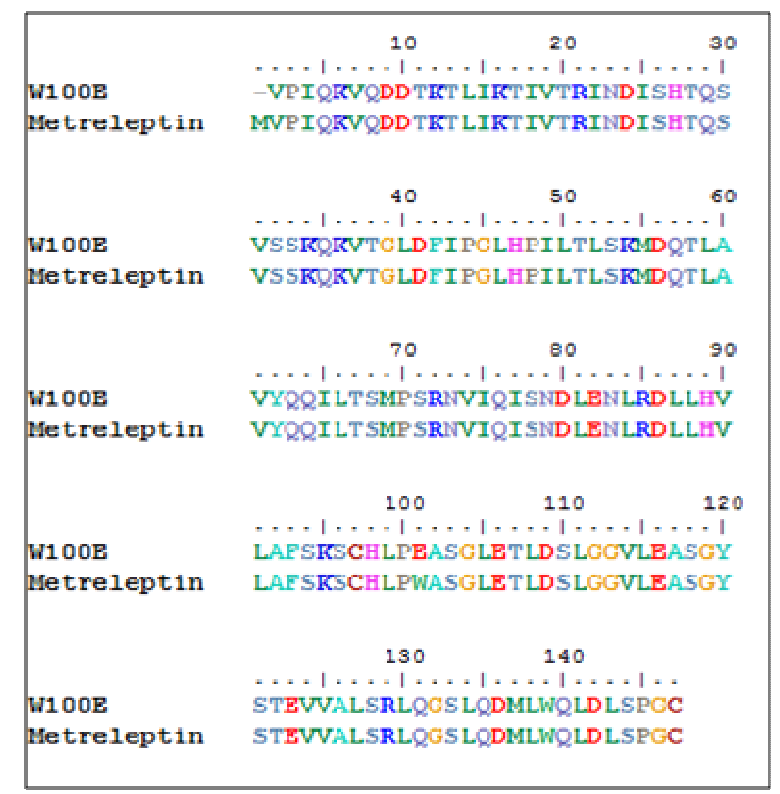

Fig. 1. Sequence alignment of Human Leptins. W100E corresponds to the construct described by X-ray crystal-lography (Lo et al., 2005), MetreLeptin is the most widely used is Leptin treatments and the sequence of W100E Leptin mutant used in this study.

Table 1. Composition of the control and test diets

\begin{tabular}{lcr}
\hline & Control $(\%)^{*}$ & $\mathrm{HF}(\%)^{* *}$ \\
\hline Protein & 28.05 & 18.23 \\
Fat & 12.14 & 7.89 \\
Lard & 0.00 & 35.00 \\
Carbohydrate & 59.81 & 38.88 \\
Total & 100.00 & 100.00 \\
Calories (kcal) & 467.50 & 314.50 \\
\hline
\end{tabular}

Male ICR mice (Biorepository of the National School of Biological Sciences) weighing 25-30 g were housed in a room at a constant temperature of $22 \pm 1^{\circ} \mathrm{C}$ and a $12 \mathrm{~h}$ light/dark cycle (lights on at 9: $00 \mathrm{AM}$ ) and were given food and water ad libitum.

All experiments were approved by the Laboratory Animal Care Commit-tee of the national school of Biological Sciences (National Polytechnic Institute) and were conducted in compliance with the Mexican Official standard (NOM-062-200-1999) technical specifications for the production, care and use of laboratory animals. Firstly, mice were distributed into four groups of 10 animals each and nourished with either standard or High-Fat/High Fructose diet (HFHF), for four weeks. Afterwards, groups 3 and 4 were dosed with human W100E-Leptin (daily subcutaneous injection of $30 \mu \mathrm{g}$ per mouse, at eight o'clock) for ten days while nurture was continued in all mice. During the whole experiment food intake and body weight gain were recorded. At the end of treatment, we continued to record these variables daily for a further week.

\subsection{Lipid Profile}

After ten days of treatment, blood was collected by retro orbital puncture and serum was prepared by centrifuging the blood at $3000 \mathrm{rpm}$ for 20 minutes. The levels of Total Cholesterol (TC), HDL Cholesterol (HDL-C) and Triglycerides (TGs) were determined by using the automatic Selectra analyzer (Model Vitalab 2), with commercial kits (RANDOX). After the whole treatment, animals were fasted for eight hours and then sacrificed. The retroperitoneal and periepididymal fat were weighed.

\subsection{Statistical Analysis}

Data were analyzed with one-way ANOVA followed by Holm-Sidak post hoc tests, with significance set to $\mathrm{p}<0.05$. Food consumption was analyzed using two-way ANOVA repeated measures tests followed by Tukey's post hoc tests, with significance set to $\mathrm{p}<0.05$. All analyses were performed using Sigma Stat (10.0).

\section{RESULTS}

\subsection{Food Intake}

In Fig. 2, we show food intake during the 10 days of treatment with human Leptin W100E. The mice that received standard diet and treated with Leptin (W100E) significantly increased their food intake (above 5 grams per day), compared to the other groups. Meanwhile, those given a diet high in fat and Fructose and Hormone treatment (HFHF + W100E) decreased their food consumption (below $4.5 \mathrm{~g}$ per day), but their calorie intake was higher. 


\subsection{Body Weight}

In Fig. 3 the body weight of mice on a high-calorie diet during treatment with W100E-Leptin is shown and compared with the other groups. Although, no significant differences were found, it is still observed that mice subjected to a High Fat/High Fructose diet plus human W100E-Leptin (HFHF + W100E) gained less weight than mice of the other treatments.

\subsection{Retroperitoneal and Periepididymal Fat}

The effect of human W100E-Leptin on retroperitoneal and epididymal fat of mice subjected to standard and high-calorie diets are shown in Fig. 4. It is observed that the mice receiving the High-calorie diet (HFHF) had higher fat content (c.a., $1.1 \mathrm{~g}$ ) than the control group (approximately $0.55 \mathrm{~g}$ ).

On the contrary, the mice receiving the W100ELeptin and High Fat/High Fructose diet (HFHF + $\mathrm{W} 100 \mathrm{E}$ ) presented less fat (about $0.85 \mathrm{~g}$ ) but did not differ significantly from group with hyper caloric diet or from the control group.

\subsection{Lipid Profile}

Figure 5 shows the lipid profile of mice subjected to normal or high-calorie diets with and without human W100E-Leptin treatment and no significant differences in levels of total cholesterol between groups of mice were observed (Fig. 5a). Regarding the triglyceride levels (Fig. 5b), there was a significant increase on mice fed with HFHF diet. In turn, those mice with the standard diet and human W100E-Leptin treatment showed a slight increase but not significantly different from the control, nor from the HFHF diet group. Interestingly, mice receiving the highcalorie diet and human W100E-Leptin showed a significant decrease in triglyceride's levels compared with the group HFHF. Fig. 5c shows HDL cholesterol levels for the four groups. The opposite effect to that described for triglycerides levels was detected, since the mice that received the HFHF diet complemented with human W100E-Leptin showed a significant increase in this variable. Variations of LDL-cholesterol between groups were not significant, even though the highest levels for the HFHF + W100E group were observed, whereas the lowest value obtained for mice with the standard diet and W100E-Leptin treatment.

\subsection{Rebound Effect}

In Fig. 6, the results of food consumption during the following week after W100E-Leptin treatment was completed are shown. It is observed that mice receiving human W100E-Leptin with normal diet show alterations in food intake since oscillations in this variable are observed after stopping treatment. The mice who received the HFHF diet and human W100E-Leptin decreased their food intake the following two days after treatment, but in subsequent days they increased their consumption to normal levels.

In Fig. 7, the increase in body weight of mice one week after treatment completion with Leptin W100E is

shown.

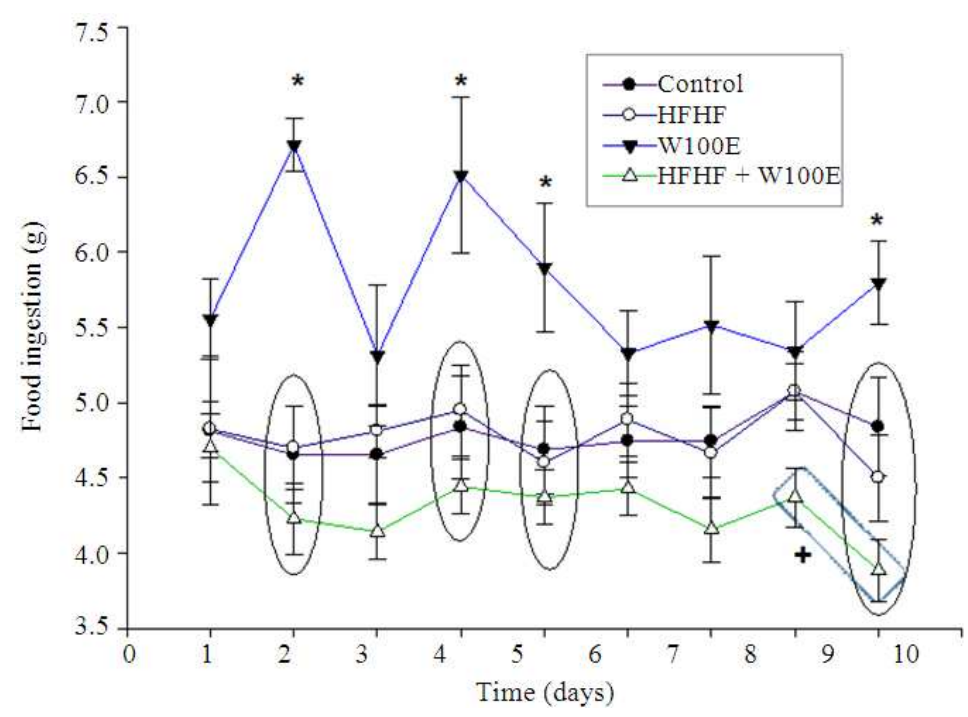

Fig. 2. Food intake of mice subjected to normal or high-calorie diet (HFHF) with and without treatment with Leptin W100E. Significant difference *p<0.05 Vs. Control and HFHF, HFHF + W100E. + p<0.05 Vs. Con-trol. Two-factor ANOVA, post hoc Holm Sidakt 
Chimal-Vega, B. et al. / American Journal of Agricultural and Biological Sciences 9 (3): 430-438, 2014

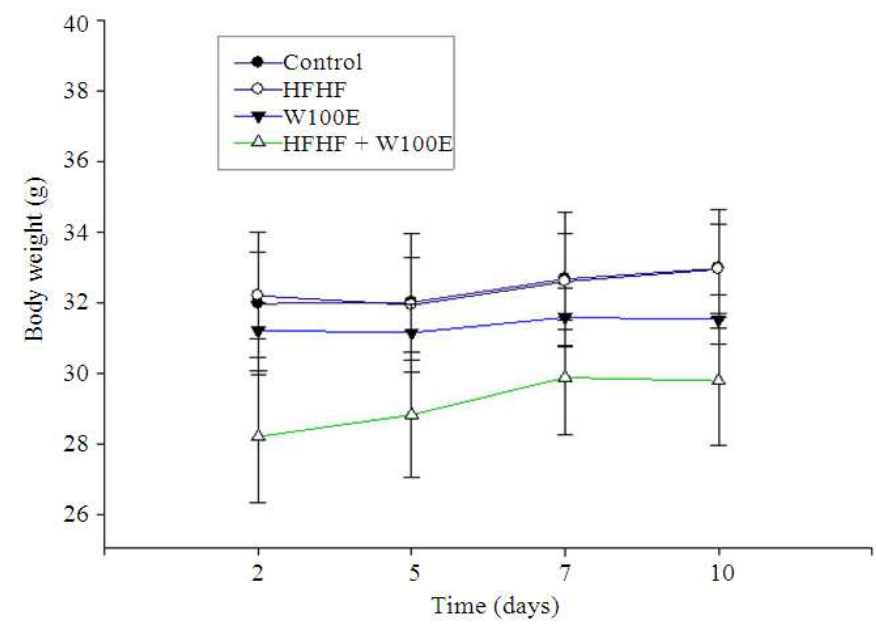

Fig. 3. Body weight of mice on a High-calorie diet (HFHF) during treatment with and without Leptin W100E. Two-factor ANOVA

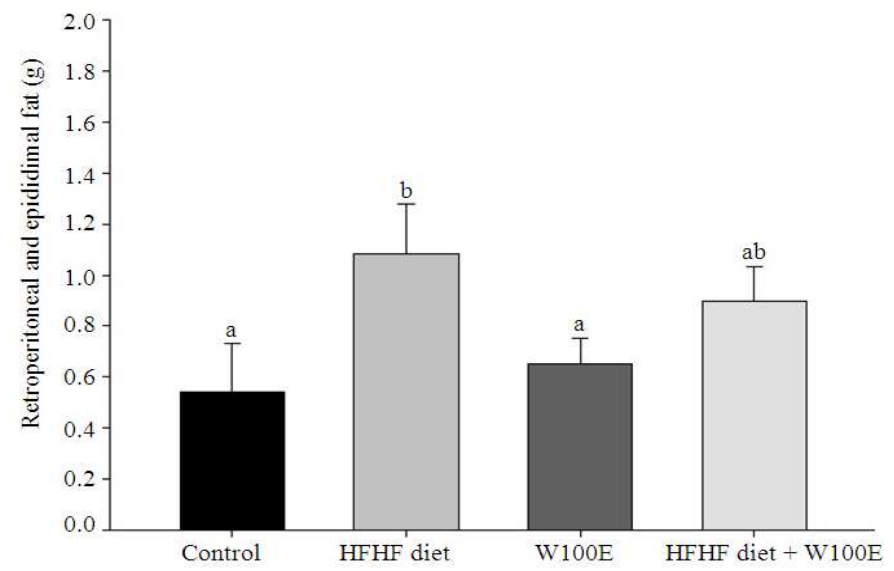

Fig. 4. Retroperitoneal and epididymal fat of mice on a high-calorie diet with and without Leptin treatment W100E. Different letters define differences between groups $(\mathrm{p}<0.05)$. One-way ANOVA, post hoc Holm Sidak test

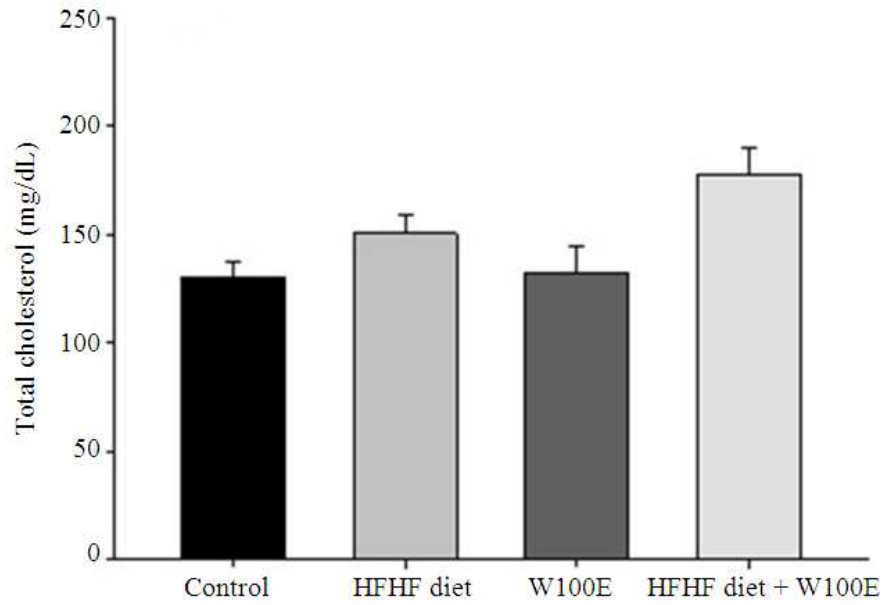

(a) 
Chimal-Vega, B. et al. / American Journal of Agricultural and Biological Sciences 9 (3): 430-438, 2014
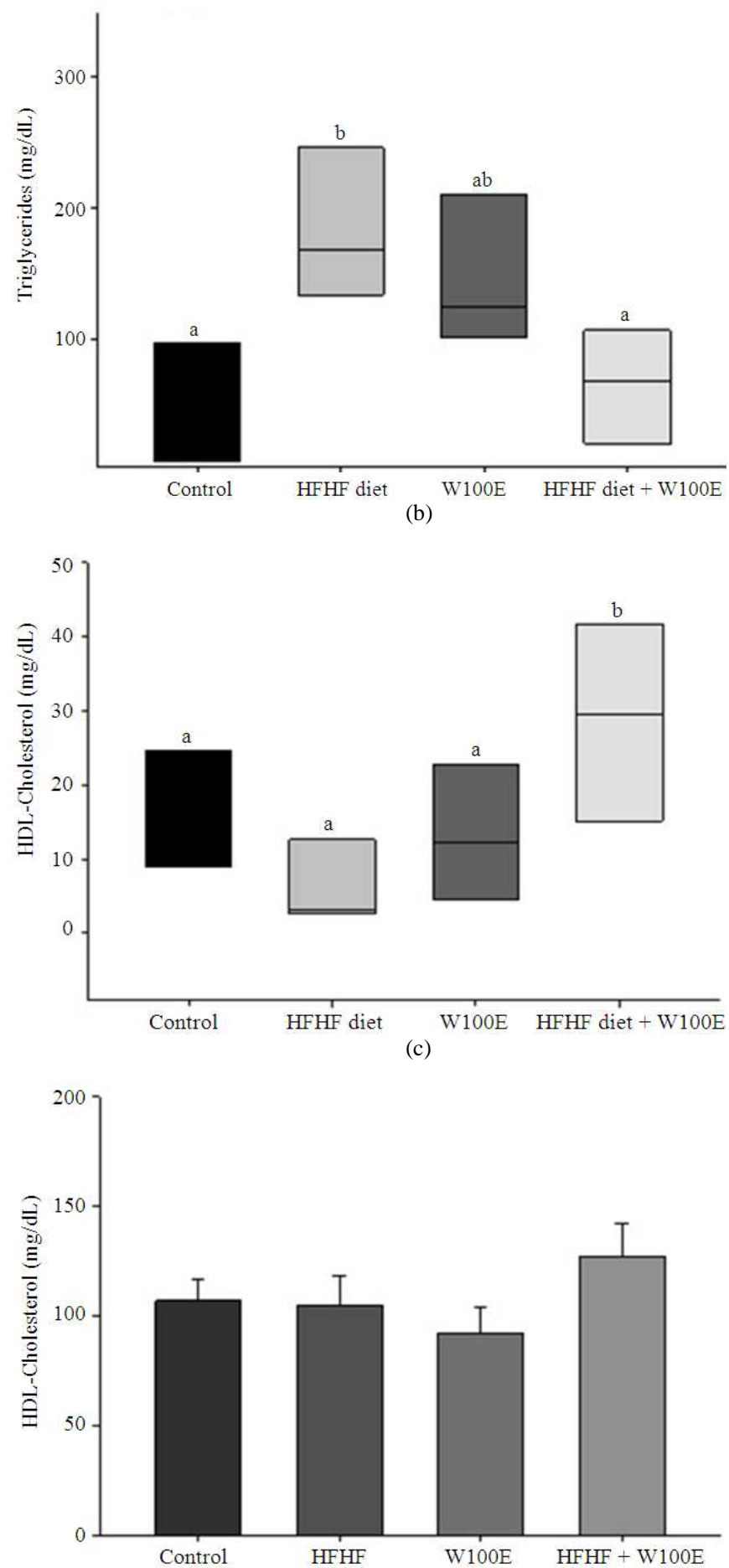

(d)

Fig. 5. Lipid profile of mice subjected to a high-calorie diet and after treatment with or without W100E Leptin. (A) To-tal- Cholesterol, (B) Triglycerides, (C) HDL-cholesterol and (D) LDL-cholesterol. Different letters define differences be-tween groups $(\mathrm{p}<0.05)$. (A) One-way ANOVA, post hoc Holm Sidak test; (B), (C) and (D) ANOVA on Ranks, Dunn's post hoc test 


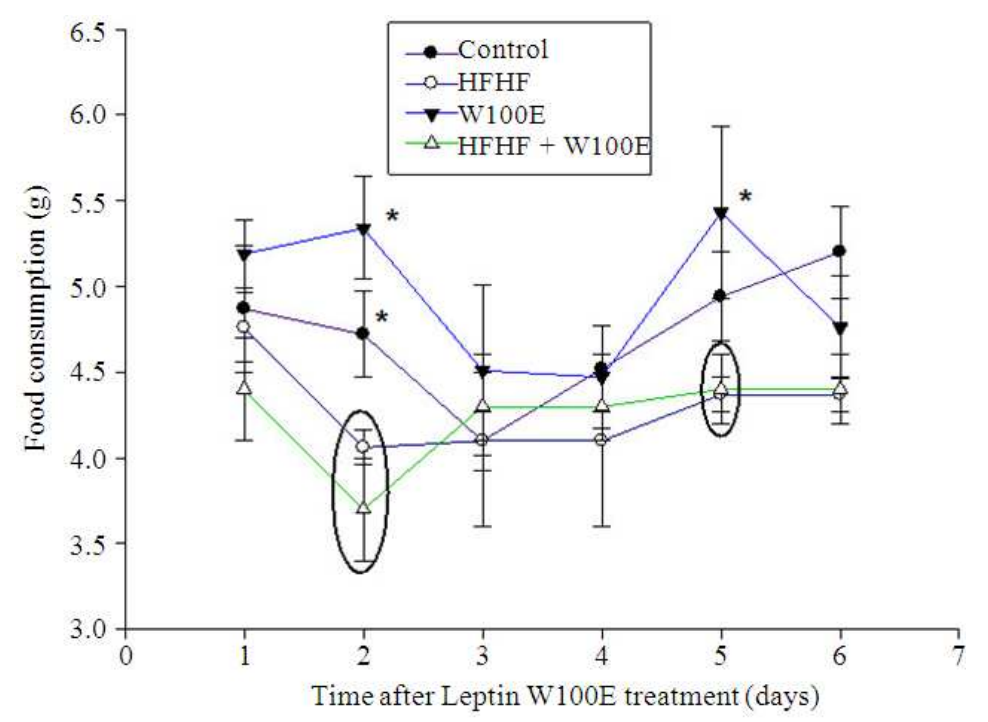

Fig. 6. Food intake one week after completion of Leptin-W100E treatment. *p<0.05 Vs. HFHF and control group. Two-way ANOVA RM, post hoc Holm-Sidak test

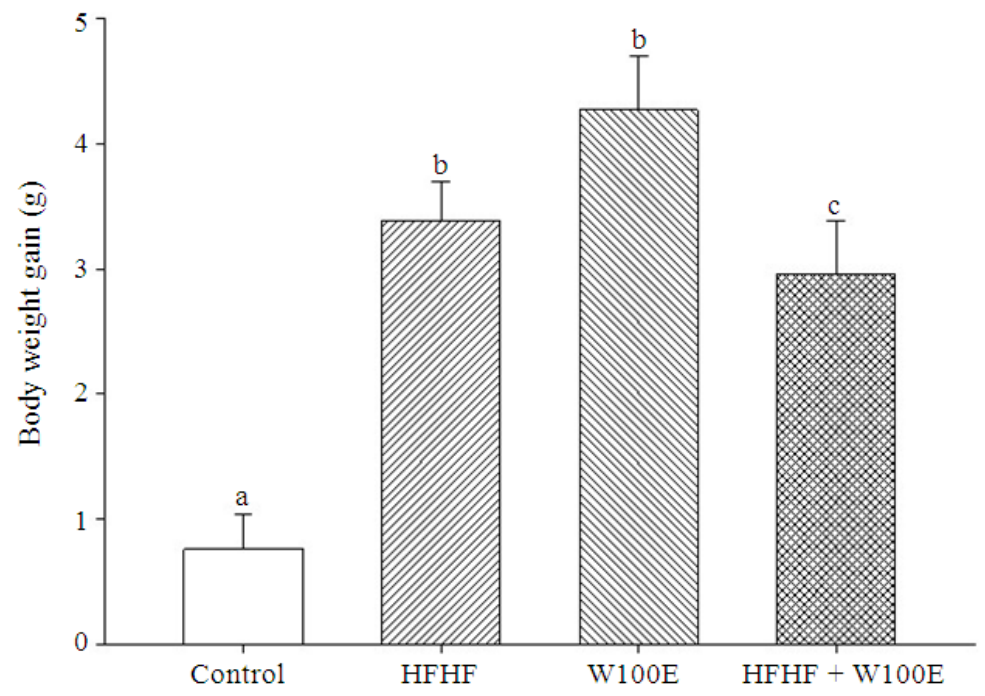

Fig. 7. Body weight gain one week after Leptin W100E treatment finished. Different letters define differences between groups $(\mathrm{p}<0.05)$. One-way ANOVA, pot hock Holm-Sidak test

All groups significantly increased the body weight compared with the control, though a lower weight gain corresponded to HFHF $+\mathrm{W} 100 \mathrm{E}$ group. Also, the gain in body weight of mice is shown one week after completing the treatment with human W100E-Leptin. Mice subjected to HFHF diet (without Leptin), standard diet with human W100E-Leptin and HFHF diet with human W100E-Leptin treatment significantly increased their body weights compared with control, although the increase was lower in the latter group.

\section{DISCUSSION}

Obesity is a complex multi factorial chronic disease that develops from an imbalance between energy intake and energy expenditure. Abnormal or excessive 
accumulation of energy as fat in adipose tissue is the result of a combination of physiological, psychological, metabolic, genetic, socioeconomic, cultural and emotional factors (Blancas-Flores et al., 2009). It is well recognized that combating obesity is a difficult problem that cannot be solely solved by trusting in the will of obese and overweight individuals. Therefore, several efforts are in progress to propose plausible alternatives to help in obesity treatment. Among them Leptin, since it discovery (Zhang et al., 1995), has been considered as a potential alternative treatment against obesity. Nevertheless, the original enthusiasm towards was vanished, when it was observed that commonly obese and overweight individuals show augmented levels of circulating Leptin. During these two decades, we have learned about signaling pathways, Leptin resistance phenomenon, its relationship with other important hormones and how it might participate in other physiological processes, like bone formation, gonadal development, among many other functions.

Regarding the structure of Leptin, the only crystallographic coordinates available of this hormone peptide have been obtained by substituting a tryptophan at position 100 by a glutamic acid (Zhang et al., 1997). This mutant was described to show similar biological activity, but with enhance solubility and feasibility to crystallize. We made a thorough search on reports concerning the effect in food intake, body weight, lipidic profile and rebound effect of W100E treatment in mice submitted to standard or hypercaloric diets. However, we were not able to find any reports using precisely this construct in similar studies. Commonly Leptin treatments are carried out using either metreleptin or a variety of mutants or analog constructs with different composition to W100E Leptin. Considering that a single point mutation might be sufficient to modify the conformation, stability and functionality of any protein; we were motivated to make a detailed study of how the treatment with this mutant might be helpful in treating obesity and lipid parameters in a murine model.

We observed that W100E Leptin treatment indeed reduces food intake and body weight on obese mice.

In the same group the total cholesterol levels was incremented, as well as HDL and LDL cholesterol triglycerides. On the contrary, the food intake and total cholesterol, was increased in mice with normal diet, while LDL cholesterol was reduced in this group.
These data complement our knowledge about soluble Leptin usage as treatment against obesity and associated pathologies.

\section{CONCLUSION}

The effect of W100E-Leptin is different in mice receiving a standard diet from that receiving high-calorie diet. In animals with standard diet W100E-Leptin caused greater food consumption as well as total-cholesterol levels, but body weight remained unchanged. In animals with high calorie diet, W100E-Leptin treatment decreased food intake and body weight as well as triglycerides, while HDL-cholesterol levels were increased. When stopping W100E-Leptin treatment the food consumption pattern was affected, which causes an increase in body weight in all groups compared to the control group. The rebound occurred in animals with normal diet as well as high-calorie diet. In conclusion, these results show that the use of recombinant Leptin in murine models weight loss occurs accompanied by an improvement in lipid profiles. However, subsequent studies W100E administration in humans is required to determine their therapeutic potential for the treatment of obesity and its comorbidities.

\section{ACKNOWLEDGMENT}

This work received financial support by Medix; Project entitled "Generación de variantes de Leptina humana como alternativa terapéutica en el tratamiento de la obesidad y diabetes mellitus". We also thank grants SIP-IPN 0140317, 20140266 and 20140297. B. Chimal-Vega thanks scholarships from CONACyT (04042009) and Medix.

\section{REFERENCES}

Ahima, R.S. and J.S. Flier 2000. Leptin. Annu. Rev. Physiol., 62: 413-437. DOI: 10.1146/annurev.physiol.62.1.413

Aijälä, E., M. Malo, O. Ukkola, R. Bloigu and Y.A. Kesäniemi et al., 2013. Long-term fructose feeding changes the expression of Leptin receptors and autophagy genes in the adipose tissue and liver of male rats: A possible link to elevated triglycerides. Genes Nutr. Nov., 8: 623-35. PMID: 3824831

Barrera-Cruz, A., A. Rodríguez-González and M.A. Molina-Ayalab, 2013 Escenario actual de la obesidad en México. Rev. Med. Inst. Mex. Seguro Soc., 51: 292-299. 
Bell, C.G., A.J. Walley and P. Froguel, 2005. The genetics of human obesity. Nat. Rev. Genet, Mar, 6: 221-234. DOI: $10.1038 / \mathrm{nrg} 1556$

Bence, K.K., M. Delibegovic, B. Xue, C.Z. Gorgun and B.B. Kahn et al., 2006. Neuronal PTP1B regulates body weight, adiposity and Leptin action. Nat. Med. Aug. 12: 917-24. DOI: 10.1038/nm0210-237a

Blancas-Flores, G., C. Almanza-Pérez, R.V. López-Roa, F.J. Alarcón-Aguilar and M. Cruz et al., 2009. La obesidad como un proceso inflamatorio. 3-12.

Carrillo-Vazquez, J.P., J. Lopez-Alcantar, B. ChimalVega, C.G. Benítez-Cardoza and L. Marchat et al., 2013. G-2548A Leptin promoter and Q223R Leptin receptor polymorphisms in obese Mexican subjects. Am. J. Agric. Biol. Sci., 8: 34-43. DOI: 10.3844/ajabssp.2013.34.43

Flores, M.B.S., M.F.A. Fernandes, E.R. Ropelle, M.C. Faria and J.B.C. Carvalheira et al., 2006. Exercise improves insulin and Leptin sensitivity in hypothalamus of Wistar rats. Diabetes., 55: 25542561. DOI: $10.2337 / \mathrm{db} 05-1622$

Haglund, E., J.I. Sułkowska, Z. He, G.S. Feng and J.N. Onuchic et al., 2012. The unique cysteine knot regulates the pleotropic hormone leptin. PLoS One, 7: 9-9. DOI: 10.1371/journal.pone.0045654

Houseknecht, K.L., C.A. Baile, R.L. Matteri and M.E. Spurlock, 1998. The biology of Leptin: A review. J. Anim. Sci., 76:1405-1420. PMID: 9621947

http://www.who.int/topics/obesity/en/

httRp://www.fao.org/publications ISSN 0081-4539

Lo, K.M., J. Zhang Y. Sun, B. Morelli and S.D. Gillies et al., 2005. Engineering a pharmacologically superior form of Leptin for the treatment of obesity. Protein Eng. Design Select., 18: 1-10. DOI: 10.1093/protein/gzh102

Masuzaki, H., Y. Ogawa, N. Sagawa, K. Hosoda and K. Nakao et al., 1997. Nonadipose tissue production of Leptin: Leptin as a novel placenta-derived hormone in humans. Nat. Med., 3: 1029-1033. DOI: 10.1038/nm0997-1029

Morrison, C., 2008. Interaction between exercise and leptin in the treatment of obesity. Diabetes, 57: 5345. DOI: $10.2337 / \mathrm{db} 08-0007$
Paz-Filho, C. Mastronardi, T. Delibasi, M.L. Wong and J. Licinio, 2010. Congenital Leptin deficiency: Diagnosis and effects of Leptin replacement therapy. Arq. Bras Endocrinol Metab., 54: 690-697. DOI: 10.1590/S0004-27302010000800005

Prins, J.B., 2002. Adipose tissue as an endocrine organ. Best Prac. Res. Clin. Endocrinol Metab., 16: 639651. DOI: 10.1053/beem.2002.0222

Sánchez, J.C., 2005. Perfil fisiológico de la leptina. Colombia Médica. 42: 26-38.

Seuk Moon, H., G. Matarese, A.M. Brennan, J.P. Chamberland and C.S. Mantzoros et al., 2011. Efficacy of metre leptin in obese patients with type 2 diabetes: Cellular and molecular pathways underlying leptin tolerance. Diabetes, 60: 16471656. DOI: $10.2337 / \mathrm{db} 10-1791$

Shapiro, A., M. Matheny, Y. Zhang N. Tümer and P.J. Scarpace et al., 2008. Synergy between Leptin therapy and a seemingly negligible amount of voluntary wheel running prevents progression of dietary obesity in Leptin-resistant rats. Diabetes, 57: 614-622. DOI: 10.2337/db07-0863

Sowers, J.R., 2003. Obesity as a cardiovascular risk factor. Am. J. Med., 115: 37-41. DOI: 10.1016/j.amjmed.2003.08.012

US 2013/0203661 A1, [0049] Mature Human Leptin form 1 with $\mathrm{N}$-terminal methionine (also known MetreLeptin, or A100).Aug. 8, 2013.

Varnerin, J.P., T. Smith, C.I. Rosenblum A. Vongs and M.R. Tota et al., 1998. Production of Leptin in Escherichia coli: A comparison of methods. Protein Exp. Purif., 14: 335-42. DOI: 10.1006/prep.1998.0978

Vatier, C., J. F. Gautier and C. Vigouroux, 2012. Therapeutic use of recombinant methionyl human Leptin. Biochimie, 10: 2116-2125. DOI: 10.1016/j.biochi.2012.03.013

Zhang, Y., R. Proenca, M. Maffei, M. Barone and J.M. Friedman et al., 1995. Positional cloning of the mouse obese gene and its human homologue. Nature, 30: 479-479. PMID: 79842

Zhang, F., M.B. Basinski, J.M. Beals, S.L. Briggs and R.W. Schevitz et al., 1997. Crystal structure of the obese protein Leptin-E100. Nature, 8: 206-209. DOI: $10.1038 / 387206 a 0$ 